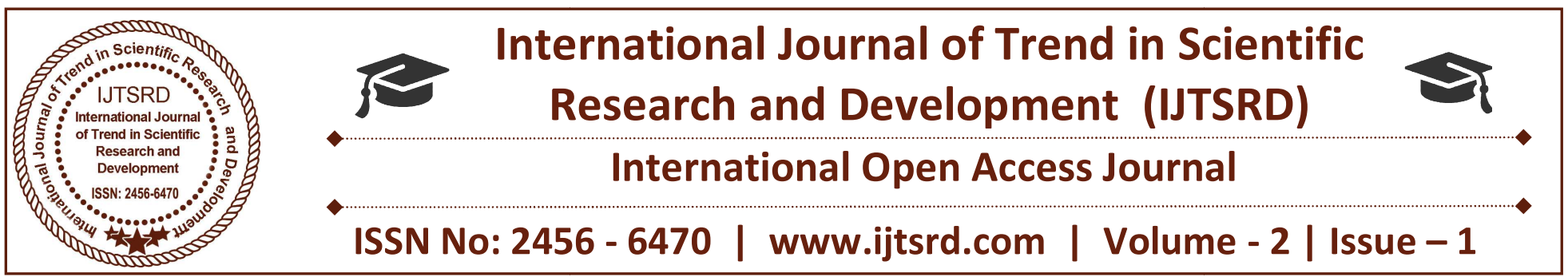

\title{
Emerging Trends in Electoral System: Revolutionary Transformation through the Information Technology
}

\author{
Kolapuri Chandrashekar \\ MA Political Science, University of Hyderabad, \\ Hyderabad, Telangana
}

\section{ABSTRACT}

70 Years Independent India's largest democracy operate through the Periodic elections. In this paper explaining electoral reforms through the information technology (IT) and Transformation of electoral management in India. This paper mainly analyses the entire IT role in the election system and the main intervention of revolutionary transformation of free and fair elections. Moreover, the paper explaining role of 21 st century Indians electoral system in citizen and voters services, electoral management, transparency and political party's participation. Information Communication Technology (ICT) developed many applications in electoral management. In addictions this paper analyse these Applications and Its Working Style. This paper explaining the importance of electronic voting machines (EVM) and the transformation of EVM system. In addition, paper explaining the emerging trends in EVM machines recent proposal of VVPATs. Analysing advantages and significances the Revolution implication of NOTA. Information Technology will soon be seeking free and fair elections of the Indian electoral system.

Keywords: $\quad$ Technology, Management, Transformation, Transparency, EVM, VVPATs, NOTA

\section{Introduction:}

India's Election Commission is the backbone of the world's largest democracy. The Election Commission of India (ECI) is proactive in selling information technology free and fair elections in India. The ECI is quick to introduce technological changes and technological improvements. These improvements have contributed to the election-speed behaviour, but have also contributed to the improvement of transparency and credibility of the entire electoral process. The use of information technology is not for general data processing, but ECI headquarters and its respective main election offices at the state / UT level head its use in innovative ways across the electoral life cycle.

The Election Commission of India has been maintaining up with technological uplifts and in the introduction of the overall electoral processes, which contributed to the speedy conduct of elections with transparency and credibility for large number of stakeholders. ECI leveraged on potential of ICT in improving the overall performance of resolving many issues. With its diverse stakeholders, ECI has taken up the e-Governance initiative by adopting IT enabled seamless operations throughout all offices in the country, which intends to build a core set of integrated IT applications covering all functions serving various stakeholders during pre-election, election, postelection and non-election phases. The initiative primarily intends to transform the front-end and backend operations of the ECI and CEO offices. Over a period, more than 51 IT applications have been innovated and developed by ECI along with the large number of applications developed by the state and district offices. The ECI intends to go to the next phase in leveraging the key functions by consolidating the functions of a centralized, integrated application, which will provide support to key functions such as Electoral Roll Management, Election Expenditure Management, Elections Planning \& Management, and Election Monitor etc. 


\section{Electoral system transformation through ICT}

The Election Commission of India has developed several applications in the Election Management and Non-Corruption Electoral System. The 51 applications for transparency of the electoral system developed in ECI. This paper is dived into four parts. Citizens, second monitoring, third information and last political parties. These four are providing with centric service.

\section{Citizens/Voters:}

* Electoral portal-100\% availability throughout the year and running without hacking

National voters service -Voter name searching national wide. Apply for registration, correction, modification. View details of Polling Booths, Assembly Constituencies, and Parliamentary constituencies. Get contact details of Booth Level and other officials. Get a link to websites of states / UTs View audio-visual films to get educated about election processes, polling processes, use of EVM etc.

National grievance service - Complete G to C interface for providing seamless services to submit grievance by citizens. Provides single window common interface to the citizens for submitting their complaints. The system forwards the complaints to the appropriate authority and keeps the user informed about its progress. Call centre services are integrated. All submitted grievances are monitored at the higher level. The complainant can monitor the progress of the status and track the status. SMS based information system for communicating with the complainant and the officials responsible for resolution. Analysis on complaints registered for election process improvement. Facility of accepting images and video along with complaints filed.

Polling stations -Location with google map. It is a web-based module to help users find their polling station location on Google map. Google map is available as service and is gaining a popularity now. The names of election officials (CEOs, DEOs, EROs, and BLOs along with their mobile numbers) are also displayed for polling booths. The electoral roll in pdf format of State / UT has also linked with them.
* E-Rolls in pdf - Go to www.nvsp.in and select "search your name on the election roll". Fill out the given form and click on "View your election officers" next click on "e-roll".

Voter's Educations - Voter Education Channel is Educating new Voters and Giving Information on election processes. In addition to educating use of EVM \& VVPAT.

* Results - Election Results \& Statistics An analysis of the trends and results on counting day. Also, create Round wise schedule data, Round wise votes polled against each candidate. In addition, facilitate postal ballot votes polled against each candidate. Numbers, bar charts, and pie charts declare last results. Various Report Provided.

\section{Electoral Management:}

ERMS - The ERMS (Electoral Roll Management System) will cover the entire process of Electoral Roll preparation for the State from the Electoral Roll Revision data management to the final electoral roll publishing. A cluster of window/web based applications. Covers entire process from draft roll preparation, roll revision, registration, and correction and data modification to electors Photo Identity Card (EPIC). Following tools such as Search Facility, Voter Slip generation (Online / Mobile), and Tracking status of the submitted application. Format 1 to 8 reporting module, Database Error finding module and Rationalizations of Polling Station etc.

* EVM Tracking Application - Centralized database for CU and BU's distributed across all over India. CEO / DEO / Warehouse In-charge / ECI Admin Levels / BEL / ECIL. Allows Tracking of CU / BU / VVPAT and their location. Create and enter the warehouse details and CU / BU / VVPAT stock. Transfer of Units once entered do not require re-entry and keeps check of duplicate entry of units in all the warehouses across the country.

Candidate Nomination and Affidavit Management System- Capturing candidate's election statutory information and publishing it for dissemination. Capture and display candidate's affidavits. Submission of nomination \& ballot 
papers. Controlled data entry through exception reporting.

Observers Portal- To view and capture the information of Observer. Deployment status can also be seen easily. Observers can upload various types of reports on the ECI server. The notice board is available where an observer can see that there is a commission sends any notification to him. Observers can see the files uploaded by them on the portal. They can view the last deployment status or other information/reports uploaded by them.

\section{Election Expenditure Monitoring - Monitor} Candidate total expenses. The political party gives monitor Funds to the candidate. Others give monitor Funds to the candidate. Monitor Expense understated or not. Monitor Candidate expenses exceed ceiling amount or not. EEMS Dashboard with graphs, charts and MIS analysis reports.

* Election monitoring Dashboards- Pre-poll, Pollday, Post-Poll. Trends and Result. Consolidation (post-poll statistical analysis). GIS Map based Reports using SSRS. Interactive drill down and drill through reports. Android Mobile App for sending information in real time. Predefine SMS Format for collection information. Alert system using Push / Pull SMS Technology. Find the exact location on Google Map if the incident happens.

* Poll Day Monitoring System- Poll Day Monitoring reports can be submitted via Mobile or through Web. Higher mobile penetration benefits managing time schedules. Help on the compilation for decision-making. Helps in populating decisions taken to a large number of concerned officials working in the field. Provides a mechanism of smart governance of elections

\section{Transparency:}

ECI playing a crucial role in transparency in information sharing through the ICT

Webcasting - Trends and Result Dissemination. Open source based Framework for webcasting. Check on untoward activities and help to bring about complete transparency. Live broadcast. Used for awareness to the users.
Trends and Result Dissemination- For trends and results dissemination during and after counting an application has been provided at all the counting centers on counting day. Round wise schedule data round wise votes polled against each candidate for all rounds. Postal ballot votes polled against each candidate are entered and time to time trends and results are declared through numbers, bar charts and pie charts ( for the graphical view). The various report is provided for monitoring progress of data entry.

\section{* Candidate Nomination Details}

\section{Candidate Affidavit Details}

Candidate List of Political Parties and Election Symbols- Constitutions of Political Parties. Recognition \& De-recognition of parties. Dispute, Merger etc. Contribution \& Expenditure Reports. Annual Audit Reports. Transparency Guidelines \& Current Instructions and Political Parties expenditure Details.

\section{Candidates \& Political Parties}

* Candidates Affidavits submission system Candidates can file affidavits online along with nomination forms. Assets and liabilities of candidates can be monitored properly with ease. Easy to publish on web and social media.

* Political parties' registration system-Political Party and Free Symbol Update Application. For Inserting and Distribution of New Parties and Elements Identical Details. Candidate.

* Expenditure Submission System-Facility for candidates to file their Abstract Statement of Election Expenditure online. Details of expenditure and source of funds are captured for further analysis. Candidates can easily register themselves through election commission website $\&$ file expenditure details.

* Vehicle Requisition System-Vehicle management system for issuance of vehicle requisition. Capturing of the vehicle details with the address and the number of bank details from one district to another district etc.

* Meeting/Rallies Permission Requisition SystemA single window system for Candidates and 
International Journal of Trend in Scientific Research and Development (IJTSRD) ISSN: 2456-6470

political parties to apply for permissions (meetings, rallies, vehicles, temporary election office, loudspeakers, helicopters etc.). Facilities applying, processing, granting and monitoring permissions

\section{Dynamic change electoral system EVM}

EVM or Electronic voting machines are used to vote without disclosing your identity. It is used in the Indian General and State Elections. It replaced paper ballots in the general elections in the local, state and India. The EC announced that all the electoral environments enabled by the Voter Verified Paper Audit Trail (VVPAT). EC has sanctioned Rs 3,174 crore for purchase of 16, 15,000 VVPATs. Check out the life cycle and safety features of the machine here

\section{Advantages of EVMs}

The introduction of EVM resulted in substantial cost reduction, which eliminated the need for production and printing of ballot papers. These machines save nearly 10,000 tonnes of ballot paper (200,000 trees) in every national election. A substantial reduction in expenditure comes when it comes to transport, storage, and counting staff. The main progress to the voting calculation process is to make results in 2 to 3 hours against 30-40 hours in the ballot paper system.

A large number of EVMs have received substantial assistance in the country where the voter struggles to vote in the electoral ballot system. EVMs in the movie, all they need to do is press the button against the candidate of their choice and enter their vote. These machines also reduced the possibility of bogus voting.

\section{Criticism of EVMs}

Although the Election Commission has conducted the EVMs as one of the most depressing voting machines in the world, the security flaws in these machines have been brought back and forth. Many security analysts have rejected EVMs 'fraud.' The 'criticism' by the commission rejected the argument, the challenge of the machine was challenged by many. Promoting EVMs encouraged American scientists to develop a technique to hack into these machines. The BJP leader Subramanian Swamy later called for an investigation into the safety and security of EVMs.
Voter verifiable paper audit trails (VVPATs)

The Election Commission has allocated Rs 3,174 crore to buy 16.15 lakh electoral certificates in the 2019 Lok Sabha polls. During this time, the 2017 Assembly elections will be debated on EVMs (electronic voting machines).

\section{Background}

EVMs were first used in Kerala Assembly elections in 1982, but it was the first time in the 1992 Lok Sabha elections. EVMS voting system simplified. This has led to a serious decline in electoral fraud, including rigging and stuffing of ballot boxes. VVPATS is used in certain constituencies to verify EVMs with a paper trail. Election Commission vs SubrahmanyaSwamy, 2013, Supreme Court VVPAT is directed to the EC to introduce "Free and Fair Election Mandatory" and phase-wise VVPAT.

\section{Advantages}

The VVPAT machine additionally allows EVM results to be cross-checked by a paper audit, completing another layer of independent manufacturers. It serves as an additional barrier to change or destroy votes.

\section{NOTA (none of the above)}

NOTA is an option in the list of candidates in an electronic voting machine (EVM). If a voter is not satisfied with candidates nominated by political parties in an election, their dissatisfaction can be entered through the NOTA. This is a negative voting form. NOTA is an expression of the secret right. It is also part of Article -19 (Freedom of Expression and Speech). This is not a right but a right to refuse.

\section{Background}

In 2001, Secretary to the Election Commission of India addressed a letter to the Ministry of Law and Justice to correct the serious shortcomings for the right to refuse the right to refuse. However, no action was taken. People's Union for Civil Liberties. In the Supreme Court of the Union of India judgment, the provisions of the Election Code of 1961 (41), 41 (3) $\& 49(\mathrm{O})$ Create an awareness on the above (NOTA) and the electronic voting machine (EVMs). Adverse voting in the Indian parliament is a frequent choice. 


\section{Significance}

It helps to maintain the secret of valid votes. Negative voting encourages people who are not satisfied with any of the candidates who have expressed their request and turned up to reject all contestants. This will help prevent voucher voting in the name of voters who have voted to record their protest. The nominal number of nota votes that emphasize political parties to nominate candidates.

\section{Conclusion:}

Indian electoral system facing this problem before the electoral management system. After ICT, the ECI will have full electoral management. When information technology is not in the electoral system, such rigging and counterfeit voting problems arise. In the electoral system ICT is coming into the largest democratic system of EVM machines introduced by many changes. The electoral system is likely to go to every polling station.The NOTA recognizes the correct principle of rejecting India's first term as a revolution in the Indian electoral system and the PUCL of the Supreme Court of India has supported the PUCL. This "no judgment" in the 2014 elections and the choice of several state elections held since passing this verdict. Without IT, Developed countries are free and fair elections cannot be imagined.

\section{REFERENCE:}

1. ICT 2025 - Vision Document by ECI

2. Eciection commission of india official web site http://eci.nic.in/m/home.html

3. EVMs : Securing Fair and Free Elections by Shubhojit on September 19, 2014

http://www.elections.in/political-corner/evmssecuring-fair-and-free-elections/

4. IT \& Automation division election commission of India

5. Nota in India: An Electoral Renaissance? By ApurvaPrabhakar

6. What is an EVM? How does it work? http://indianexpress.com/article 